\title{
Trends in diagnosis of hydrophilic pseudofungal organism Rhinosporidium seeberi- Old to Recent Approach
}

\author{
Uneza Husain $^{1 *}$ (D), Ragini Tilak ${ }^{1}, K^{2}$ tan Priyadarshi ${ }^{1}$ and Sushil Kumar Aggarwal ${ }^{2}$ \\ ${ }^{1}$ Department of Microbiology, Institute of Medical Sciences, Banaras Hindu University, Varanasi, Uttar Pradesh, \\ India. \\ ${ }^{2}$ Department of Otorhinolaryngology, Institute of Medical Sciences, Banaras Hindu University, Varanasi, Uttar \\ Pradesh, India.
}

\begin{abstract}
Rhinosporidiosis is a granulomatous disease with a chronic course, the etiological agent being Rhinosporidium seeberi which usually causes the development of localized lesion in the mucosa of the nose, conjunctiva, and urethra. The disease is prevalent in South India and Sri Lanka although case reports are evident from many parts of the world like Europe, America, and Africa. In the present study, we are reporting a case of rhinosporidiosis elaborating its clinical features, diagnostic modalities, and treatment. Since R.seeberi is not a successfully cultivable organism, in vitro susceptibility of drugs remains a concern. The main focus of the present study is on molecular detection of $R$. seeberi which can be helpful in the future for early diagnosis and prompt treatment of such cases.
\end{abstract}

Keywords: Rhinosporidiosis, R.seeberi, nasal mass, strawberry appearance

*Correspondence: uneza47@gmail.com

(Received: January 12, 2020; accepted: December 08, 2020)

Citation: Husain U, Tilak R, Priyadarshi K, Aggarwal SK. Trends in diagnosis of hydrophilic pseudofungal organism Rhinosporidium seeberi- Old to Recent Approach. J Pure Appl Microbiol. 2020;14(4):2295-2297. doi: 10.22207/JPAM.14.4.07

(C) The Author(s) 2020. Open Access. This article is distributed under the terms of the Creative Commons Attribution 4.0 International License which permits unrestricted use, sharing, distribution, and reproduction in any medium, provided you give appropriate credit to the original author(s) and the source, provide a link to the Creative Commons license, and indicate if changes were made. 


\section{INTRODUCTION}

Rhinosporidiosis is a non-contagious ${ }^{1}$ chronic granulomatous disease ${ }^{2}$ with mucocutaneous involvement. It is caused by Rhinosporidium seeberi ${ }^{2}$, a taxonomically debated endo-sporulating ${ }^{3}$ aquatic eukaryotic organism, ${ }^{4}$ which does not grow on synthetic media. The disease is endemic in South Asia particularly South India and Sri Lanka. ${ }^{5}$ Nasopharynx and palpebral conjunctiva are common sites affected with the rare occurrence of dissemination. Since the disease is prone to recurrence ${ }^{6}$ hence follow-up of patients is essential in such cases. This study emphasizes on molecular diagnosis of $R$. seeberi as part of evaluating modern techniques for the purpose of better patient care.

\section{METHODS}

A 13 yr old female presented with a history of slow-growing right-sided swelling in the nose along with unilateral nasal obstruction, bleeding, and discharge. On examination, the swelling was friable, polypoidal with a strawberry appearance. The endoscopic excision of the nasal mass was done. Direct smear examination using Potassium Hydroxide ( $\mathrm{KOH})$ mount and histopathological staining with Gomori's Methenamine Silver and Periodic acid-Schiff stain were performed. The specimen was cultured on paired Brain Heart Infusion blood agar and Sabouraud dextrose agar at $25^{\circ} \mathrm{C}$ and $37^{\circ} \mathrm{C}$. DNA extraction was carried out from nasal tissue using Qiagen kit and PCR was performed using R.seeberi specific primers F1-fw (CAAGTCTGGTGCCAGCAGCC) and F2-rev

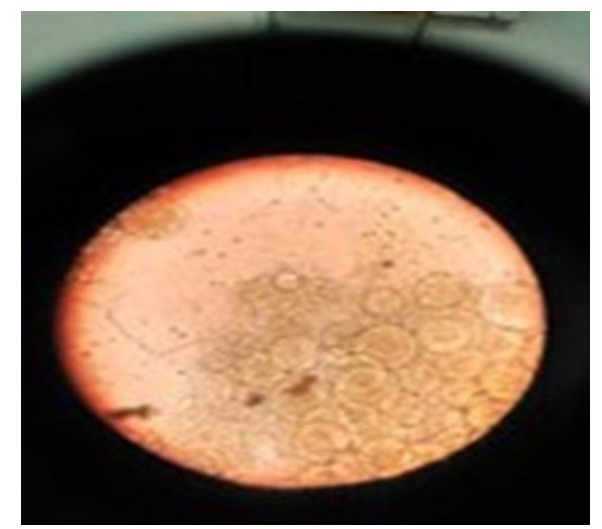

Fig. 1. $\mathrm{KOH}$ mount: sporangia filled with spores
(GATTTCTCGTAAGGTGCCGA) ${ }^{7}$ and the amplified product was detected by gel electrophoresis. The sequencing of the amplicon was also done.

\section{RESULTS}

Bacterial and fungal culture results were negative. On $\mathrm{KOH}$ mount and histopathological stains, sporangia of R.seeberi showing endospores were visualized [Fig.1]. Consensus PCR with DNA obtained from the digest of nasal polyp infected with $R$.seeberi produced an amplification product of the expected size ( $\sim 50$ base pair) as visible on gel electrophoresis [Fig.2]. It was successfully confirmed by sequencing.

Lane 1

Lane 5

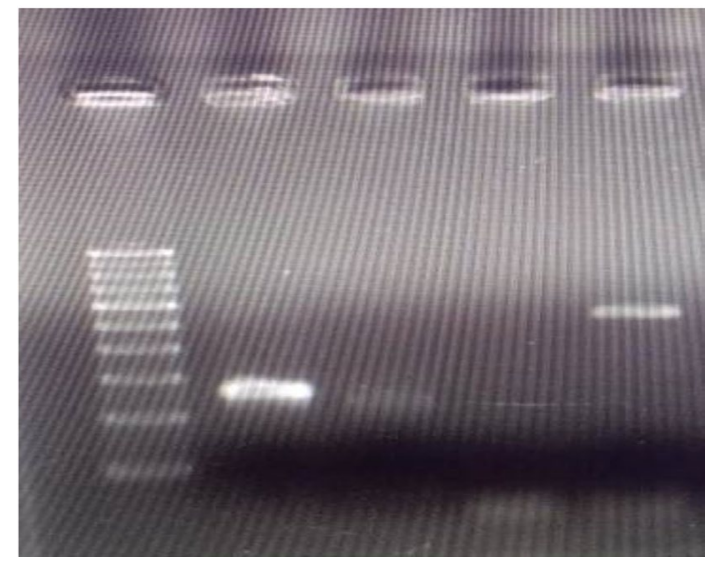

- Lane 1: 100 bp DNA ladder

- Lane 5: PCR amplicon ( 550bp) using primers specific for Rhinosporidium seeberi

- Lane 4: Negative control

Fig. 2. Gel electrophoresis image of the PCR amplicons

\section{CONCLUSION}

Nasal rhinosporidiosis may mimic neoplasm in its clinical features hence it is of paramount importance to diagnose it correctly. Local surgical excision is the mainstay of treatment which was successfully done in this case.

\section{ACKNOWLEDGMENTS}

I would like to extend my special thanks to all of the technical staff of the Department of Microbiology -Institute of Medical Sciences, Banaras Hindu University for their co-operation and help. 


\section{CONFLICT OF INTEREST}

The authors declare that there is no conflict of interest.

\section{AUTHORS' CONTRIBUTIONS}

All authors listed have made a substantial, direct, and intellectual contribution to the work.

\section{FUNDING}

\section{None}

\section{DATA AVAILABILITY}

The datasets analyzed during this study are included in the manuscript.

\section{ETHICS STATEMENT}

The study was performed after approval from the Institutional Ethics Committee and informed consent.

\section{REFERENCES}

1. Prabhu SM, Irodi A, Khiangte HL, Rupa V, Naina P. Imaging features of rhinosporidiosis on contrast $\mathrm{CT}$. Indian J Radiol Imaging. 2013;23(3):212-8. PMID: 24347850; PMCID: PMC3843328. doi: 10.4103/09713026.120267
Das S, Kashyap B, Barua M, Gupta N, Saha R, Vaid L, Banka A. Nasal rhinosporidiosis in humans: new interpretations and a review of the literature of this enigmatic disease.Med Mycol. 2011;49(3):311-315. PMID:20954821. doi: 10.3109/13693786.2010.526640

3. Chander J.Rhinosporidiosis. Textbook of Medical Mycology,4th ed. New Delhi, Jaypee Brothers Medical Publishers;2017:811.

4. Gupta N, Singla P, Pradhan B, Gurung U. Lacrimal sac rhinosporidiosis: case report and review of literature with a new grading system to optimize treatment. Saudi J Ophthalmol. 2019;33(3):283-290. PMID: 31686971; PMCID: PMC6819728. doi: 10.1016/j. sjopt.2019.05.002

5. Singh I, Lalrinmawii, Phogat D. Recurrent rhinosporidiosis: a case report. J Otolaryngol ENT Res. 2018;10(6):298-300. doi: 10.15406/ joentr.2018.10.00366

6. Khan I, Gogia S, Agarwal A, Swaroop A. Recurrent rhinosporidiosis: coblation assisted surgical resection-a novel approach in management. Case Rep Otolaryngol. 2014;2014:609784. PMID: 25574413; PMCID: PMC4276699. doi: 10.1155/2014/609784

7. Fredricks DN, Jolley JA, Lepp PW, Kosek JC, Relman DA. Rhinosporidium seeberi: a human pathogen from a novel group of aquatic protistan parasites. Emerg Infect Dis. 2000;6(3):273-282. PMID: 10827117; PMCID: PMC2640875. doi: 10.3201/eid0603.000307 